\title{
ASSESSMENT OF DEVELOPMENT AND ROLE OF ONE DAY SURGERY IN SLOVAK HEALTHCARE SYSTEM
}

\author{
Zelnik S. ${ }^{1}$, Murajda L. ${ }^{2}$, Buchancova J. ${ }^{2}$ \\ ${ }^{1}$ Department of One Day Surgery, ZILPO Ltd., Zilina, Slovakia \\ ${ }^{2}$ Department of Public Health, Jessenius Faculty of Medicine, Comenius University, Martin, Slovakia
}

\begin{abstract}
The aim of this article is to describe the development of one day surgery (ODS) and assess its role within the Slovak healthcare system.

ODS is a surgical healthcare system based on single treatment of a patient or single diagnostic procedure when performing this healthcare intervention enables dismission of patient in stabilized state in 24 hours.

During 1997-1999 the first healthcare facilities of ODS were established in the Slovak Republic. Since then the number of ODS centers has grown to 54. Currently, some $8 \%$ of all operations in Slovakia, mainly surgical and ophtalmological, are done via ODS.

The authors suggest that, if possible, ODS is an economic option regardless of medical specialty. They expect an increase of facilities performing ODS within existing health structures, establishment of new facilities for ODS and a overall increase in number of ODS interventions in Slovakia in near future.

As a conclusion, the authors highlight a possibility of pregradual experience of medical students with ODS and its benefit in dissemination of understanding and positive attitude towards the ODS methods.
\end{abstract}

Key words: one day surgery, Slovakia, regional distribution, cost, types of operations

\section{INTRODUCTION}

One day surgery (ODS) was first used in 1909 when Dr. Nichol, a paediatric surgeon, performed a successful one day surgery in Glasgow. The professional public did not accept his approach that time, what resulted in its delayed use. In 1970 there was established the first autonomous unit of ODS in Arizona (1).

ODS is a surgical healthcare system based on single treatment of a patient or single diagnostic procedure when performing this healthcare intervention enables dismission of patient in stabilized state in 24 hours. In the world, this type of healthcare is known as „Tages Klinik“, „One day care“, „One day surgery“ or ,jednodenní chirurgie“ $(2,3,4)$.

There exist two types of facilities performing ODS. One is an autonomous, fully equipped and independent unit. The second one is a so-called integrated unit - a ward within a hospital (1).

There are various proportions of ODS in healthcare systems of different countries. Furthermore, these proportions have evolved through the recent 20-30 years. As it was mentioned during the 5th Symposium of SAJCH (Slovak association of one day surgery) in Bratislava in 2009, in the European Union countries in 2005 some $60 \%$ of all surgical operations were performed as ODS. Even higher percentage is known from Canada and the USA, where the use of ODS has reached 87 , respectively $84 \%$. However, 1980 s in the USA it was only 45\%. In Canada in 1999 it was 60\%. Similar situation is in Australia, where in 1999 it was $40 \%$. The proportions of ODS in all three mentioned countries have almost doubled since then.

On the contrary, in Slovakia some 8\% of surgical operations in 2008 were done as ODS.

The aim of this article is to describe the development of ODS and assess its role within Slovak healthcare system.

Address for correspondence:

Štefan Zelník, MD, ŽILPO, Vysokoškolákov 31, 01008 Žilina, Slovakia, zelnik@zilpo.sk 


\section{DEVELOPMENT OF ODS IN SLOVAKIA}

During 1997 and two consecutive years the first healthcare facilities of ODS were established in the Slovak Republic. Later on, in 2002, the Slovak association of one day surgery was constituted. Eva Vidová MD became its president. In 2003 a list of 174 surgical procedures performed via ODS already existed. This list was enlarged in 2005, comprising plastic surgery and laparoscopical cholecystectomy. The list has grown constantly since then.

However, the proportion of ODS from all surgical operations remains relatively small, approximately 7-10\%. Comparably, the number of healthcare facilities performing ODS grows very slowly - and only in bigger regional centers - due to lack of motivation criteria and conditions. Recently, there are 54 centres of ODS in Slovakia. Establishment of an ODS center poses a high initial financial burden (operation theatre with necessary background), demanding financing of running and limited reimbursement from healthcare insurance companies.

The precise number of ODS centers is hard to know. Our knowledge is based on statistics of the state health insurance company, the General Insurance Company (VšZP). There are some minor centers which are not financed by this company, therefore not registered. Furthermore, to assess the situation according the insurance company statistics is complicated because not all of the registered providers really do perform a considerable proportion of ODS (thus making the real picture of ODS performance questionable).

In Figure 1 is presented a distribution of ODS centers in eight Slovak regions.

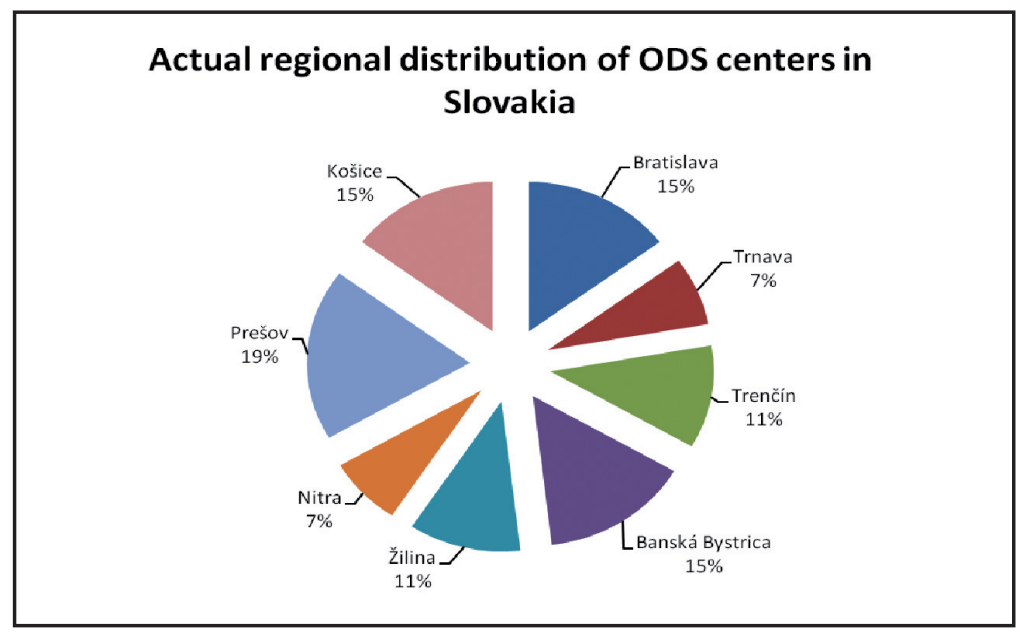

Figure 1. Distribution of one-day-surgery centers in eight Slovak regions.

The distribution seems balanced. A little surprisingly, the eastern region Prešov accounts for more ODS centers than more developed and even more populated regions in western part of the country (natural tendency for better resource allocation?).

Regarding the specialities and types of operations performed via ODS, we did a small survey among the ODS centers. An average rate of complications at all operations in 2008 was under $0.8 \%$. Results are shown in Table 1. 
Tab 1. Types of operations performed at one-day-surgery centers. Slovakia, 2010.

\begin{tabular}{|l|l|}
\hline \multicolumn{2}{|l|}{ Proportion of operations performed at ODS centers in Slovakia (\%) } \\
\hline surgical & 49.5 \\
\hline ophtalmological & 26.7 \\
\hline gynecological & 17.8 \\
\hline ENT & 3.8 \\
\hline urological & 2.2 \\
\hline TOTAL & 100.0 \\
\hline
\end{tabular}

In last 5 years, the most frequent surgical operations have been operations of varices, carpal tunnels and extirpations of cutaneous and subcutaneous tumours. In ophtalmology they have been the operations of cataracts, in gynaecology histological curettage and operations for urinal incontinence, in ENT the endoscopic tonsilectomies, adenotomies, plastical operations of the septum, in urology operations of phimoses and hydrocele.

In Table 2 we present a cost summary from selected hospitals run by regional governments and from hospitals included in basic healthcare facilities network (that is the faculty and district healthcare facilities).

Tab 2. Comparison of cost of standard healthcare and ODS, selected hospitals, Slovakia 2005 - 2008.

\begin{tabular}{|l|c|c|c|}
\hline Specialty & Regional hospitals & $\begin{array}{l}\text { Hospitals of the basic network } \\
\text { (faculty or district) }\end{array}$ & One day surgery \\
\hline Surgery & $432 €$ & $996 €$ & $266 €$ \\
\hline Gynaecology & $365 €$ & $830 €$ & $232 €$ \\
\hline ENT & $299 €$ & $830 €$ & $249 €$ \\
\hline Urology & $298 €$ & $830 €$ & $249 €$ \\
\hline Ophtalmology & $365 €$ & $664 €$ & $315 €$ \\
\hline
\end{tabular}

Note: payments at hospitals (regional, faculty or district) for dismissed patients according data from General Healthcare Insurance (VšZP)

\section{ROLE OF ODS}

One day surgery is a very popular choice for many people who have to undergo a surgical intervention and they are able to stay at home after the operation.

The system of ODS is an important decision at managerial level at healthcare facilities $(2$, 5). It may be considered not only an alternative but a structurally new approach.

Despite of advantages of ODS, the key factor remains the experience of a surgeon, assuring after evaluation of an actual health condition a correct selection of patients for such diagnostic-therapeutical solution within ODS. A surgeon suggests a traditional surgical solution of more serious diseases (e.g. acute and subacute cholecystitis, varices of lower extremities related to more evident trophic changes and others) out of ODS. Similarly, also an anesthesiologist excludes from the ODS program patients with extreme obesity, serious form of diabetes mellitus and others. 
When including a patient in the ODS program, it is necessary to assess whether the further care will be provided well at home. Persons with not sufficient social background are not suitable for ODS, eventually lonely living people are not recommended as well. Patients after ODS intervention should not live too far away from the surgical healthcare facility, so that in case of complications it would be possible to transport them soon to the hospital in any season. In some cases patients from remote areas arrange an accomodation in hotels, which are closer to a hospital, or they live temporarily at their relatives.

A relation with regional home care services seems to be a crucial need and suitable solution. This care is performed by professionals trained in surgical care follow up (2).

Despite the fact that at present the ODS is only little being used in Slovakia, based on literature evidence and our survey data, we expect an increase of facilities performing ODS within existing health structures, establishment of new facilities for ODS and a overall increase in number of ODS interventions.

We think that ODS is an economic option regardless of medical specialty. The possibility to save enormous financial cost for hospitalization is one of the important factors favorizing use of ODS methods.

Similarly as Onetti et al. (2008), we are convinced that in case of possible choice, it is suitable to prioritize a ODS intervention over the traditional procedure with hospitalization.

The principles that should be kept for ODS encompass the one that the patients at inpatient wards should not be „mixed“ with patients who underwent the ODS (6).

It is necessary to create conditions for establishment of new ODS departments according regional needs.

The support for development of ODS may be accompanied with reduction of beds (7).

It is advisable to invest to promotion of ODS and to education of medical doctors, nurses and health insurance employees, as well as to monitor and publish the results from departments of ODS (8).

Treatment effect of ODS is comparable with results of standard healthcare. ODS significantly saves public resources. The promotion and support for ODS should become a public matter of interest and insurance companies should be more actively engaged in support for ODS.

In Slovakia we could also apply the experience of Seabrook et al. (1998) with teaching ODS to medical students. It would be possible to gain the basic practical knowledge in the framework of pregradual education of the medical students and to acquire practical skills in the framework of postgradual specialization study in surgical specialties. This would enhance the understanding and positive attitude towards ODS and foster its implementation in the Slovak healthcare system.

The basic condition for ODS is a skilled and qualified surgeon who is competent in autonomous decisions (9). Equally important is to guarantee management of complications, technical equipment of the operating theatre and technical and pharmacological possibilities for an anesthesiologist. After completion of all necessary requirements, it is especially important to motivate the workers involved in realization of this type of healthcare intervention.

\section{REFERENCES}

1. ADSNA - Australian Day Surgery Nurses Association. What is day surgery, 2009. Available online: http://www.adsna.info/whatis.htm.

2. Czudek S et al.: One day surgery. Bratislava: Grada 2009, 126 p. ISBN 9788024717869. [Original in Czech language]

3. Gold BS, Kitz DS, Lecky JH, Neuhaus JM. Unanticipated admision to the hospital following ambulatory surgery. Experiences after 2411 surgical interventions. JAMA 1989;262:3008-10.

4. Guzzanti E, Mastrobuono I. La day surgery e la chirurgia ambulatoriale in Italia: la storia dei primi quindici anni di attivita scientifica , istituzionale ed organizzativa e le prospettive di sviluppo. Organizzazione sanitaria, 2006;30(2):3-16. 
5. Onetti A. Applying a managerial approach to day surgery. Internat.J. Surgery 2008; 6: 41-3.

6. Colley KC, Wiliams BA, DaPos SV, Chen C, Smith RB. Retrospective evaluation of unanticipated admissions and readmissions after same day surgery and associated costs. J. Clinic. Anesthesia 2002;14(4): 349-53.

7. Roberts L. Bed costs savings in day surgery in Australia. Ambulat.Surgery 1996; 4(1):15-17.

8. Seabrook MA, Lawson M, Malster M, Solly J, Rennie J, Baskerville PA: Teaching medical students in day surgery unit:adapting medical education to changes in clinical practice. Medical Teacher 1998;20(3):111-26.

9. Brebbia G, Boni L, Dionigi G, Rovera F, Besozzi M, Diurni M, Carcano G, Dionigi R. Surgical Infections. Surgical site infections in day surgery. 2008; 7 (Suppl.2): 121-23.

Received: June, 3, 2011

Accepted: July, 14, 2011 